\title{
Application of nanotechnology in drug delivery systems for respiratory diseases (Review)
}

\author{
MING-XIN LUO, SHAN HUA and QI-YUN SHANG \\ Department of Respiratory Medicine, Anhui Provincial Children's Hospital, Hefei, Anhui 230000, P.R. China
}

Received August 13, 2020; Accepted January 28, 2021

DOI: $10.3892 / \mathrm{mmr} .2021 .11964$

\begin{abstract}
Respiratory disease is a common disease with a high incidence worldwide, which is a serious threat to human health, and is considered a societal and economic burden. The application of nanotechnology in drug delivery systems has created new treatments for respiratory diseases. Within this context, the present review systematically introduced the physicochemical properties of nanoparticles (NPs); reviewed the current research status of different nanocarriers in the treatment of respiratory diseases, including liposomes, solid lipid nanocarriers, polymeric nanocarriers, dendrimers, inorganic nanocarriers and protein nanocarriers; and discussed the main advantages and limitations of therapeutic nanomedicine in this field. The application of nanotechnology overcomes drug inherent deficiencies to a certain extent, and provides unlimited potential for the development of drugs to treat respiratory diseases. However, most of the related research work is in the preclinical experimental stage and safety assessment is still a challenging task. Future studies are needed to focus on the performance modification, molecular mechanism and potential toxicity of therapeutic nanomedicine.
\end{abstract}

Correspondence to: Dr Shan Hua, Department of Respiratory Medicine, Anhui Provincial Children's Hospital, 39 Wangjiang East Road, Hefei, Anhui 230000, P.R. China

E-mail: shanhua111@msn.com

Abbreviations: ASO, antisense oligonucleotides; AuNPs, gold nanoparticles; DCs, dendritic cells; DOX, doxorubicin; DPPC, dipalmitoylphosphatidylcholine; FDA, Food and Drug Administration; LPS, lipopolysaccharide; MERS-CoV, Middle East respiratory syndrome coronavirus; MP, methylprednisolone; NPs, nanoparticles; NSCLC, non-small cell lung cancer; PAMAM, polyamidoamide; PBCA, polybutylcyanoacrylate; $\mathrm{PEG}$, polyethylene glycol; PEI, polyethyleneimine; PLGA, poly-lactic-co-glycolic acid; PS, pulmonary surfactant; PTX, paclitaxel; SARS-CoV, severe acute respiratory syndrome coronavirus; SBS, salbutamol sulfate; siRNA, small interfering RNA; SLN, solid lipid nanocarriers; RSV, respiratory syncytial virus; VLPs, virus-like particles

Key words: nanoparticle, drug delivery systems, toxicity, inhaled nanoparticles, respiratory disease

\section{Contents}

1. Introduction

2. Application of NPs in respiratory systems

3. Conclusions

\section{Introduction}

With the rise in air pollution levels, rapid changes in lifestyle and frequent outbreaks of microbial infections, the morbidity of respiratory diseases is increasing, particularly among children and the elderly population with weakened immune systems (1). Almost 4,000,000 people die from respiratory diseases every year worldwide (2). The main respiratory diseases include acute and chronic respiratory infections, lung cancer, asthma, chronic obstructive pulmonary disease, cystic fibrosis and tuberculosis (2). Although the current diagnostic and therapeutic techniques have improved, effective treatment of severe and chronic disease is still lacking $(3,4)$. In addition, it is difficult for most drugs to reach the lower respiratory tract with adequate dose and minimum side effects. Therefore, there is an urgent need to efficiently and affordably enhance the quality of treatments for respiratory disease.

Nanoparticles (NPs) refer to particles ranging between 1 and $100 \mathrm{~nm}$ in size (5). Due to the increase in relative surface area and quantum effects, nanomaterials have special physical and chemical properties. The nanodrug delivery system is the application of nanotechnology in the pharmaceutical field, and has shown development prospects in targeted diagnosis and treatment, delaying drug release, improving drug solubility and availability, reducing drug side effects and overcoming barriers of the human body (6). The large contact surface area of airways is constructed by alveolar cells and goblet cells, whereas the main bronchiole cells consist of bronchial epithelial cells and Clara cells (mucus-producing cells). Alveolar type I epithelial cells and endothelial cells share a basement membrane. The air-blood barrier inside the lungs, with a size of 0.1-0.2 $\mu \mathrm{m}$, is comprised of epithelial and endothelial tissue sharing the basement membrane (7). The thin barrier and high permeability of this membrane make the lungs an optimal site for systemic and local delivery of drugs. Furthermore, pulmonary delivery offers improved bioavailability, biocompatibility and distribution of drugs to lung sites (8). The development of nanotechnology brings a novel broad perspective for improving the effects of treatment and diagnosis of respiratory diseases. 
However, the possible negative effects of NPs as drug carriers should also be considered. It is well known that the toxicity of inhaled NPs has a long history. For example, some NPs, similar to fine dusts and fibers in nature, may induce respiratory and cardiovascular diseases as environmental pollutants $(9,10)$. Although these data cannot be directly transferred to inhaled therapeutic NPs, before practical application, different in vitro and in vivo methods should be used in preclinical research and clinical trials to systematically detect the interaction between nanomedicines and various components of the respiratory system. In this context, the present review summarizes the properties of NPs; discusses the research status and main points of different nanocarriers in drug delivery systems for respiratory diseases, such as lung cancer, asthma, chronic respiratory diseases, cystic fibrosis, tuberculosis and respiratory infection; and discusses the advantages and limitations of therapeutic nanomedicine in the field of respiratory diseases.

\section{Application of NPs in respiratory systems}

Characteristics of NPs for efficient respiratory disease treatment design. NPs can be inhaled, diffused into the respiratory tract and deposited in the alveoli, where they can approach and interact with the epithelial cells and pulmonary surfactant (PS) (11). The characteristics of NPs, including size, shape, surface charge and wettability, serve a critical role in understanding the interaction between NPs and organisms (12). Appropriate properties can not only facilitate their direct delivery to targeted tissues and cells, but also limit their adverse side effects by decreasing drug concentrations in other tissues of the body (13).

Size. Among the different characteristics of NPs, particle size is a remarkable characteristic. Inhaled NPs are deposited on the pulmonary airway mainly via diffusional displacement by the thermal motion between air molecules and the NPs (14). The nasopharyngeal and tracheobronchial deposition of NPs have been reported to be negatively correlated with their size (15). A previous animal study in pigs performed by Murgia et al (16) revealed that only extremely small carboxylated NPs $(<100 \mathrm{~nm})$ were able to penetrate into mucus. Compared with large NPs (>100 nm), NPs with smaller size $(<30 \mathrm{~nm})$ were more suitable at penetrating biological barriers, including the air-blood barriers.

After intranasal immunization of polystyrene particles (20-1,000 nm), Blank et al (17) compared the size-dependent cellular absorption of these particles on antigen-presenting cells at respiratory sites in BALB/c mice. In the trachea and lung parenchyma, most of the smaller particles $(20$ and $50 \mathrm{~nm})$ were absorbed by dendritic cells (DCs) compared with larger ones $(1,000 \mathrm{~nm})$, and the smaller ones were also observed in lung-associated lymph nodes. However, the uptake of cells by alveolar macrophages did not depend on the size of particles and larger particles could easily be phagocytized by lung macrophages. In addition, Ghaffar et al (18) demonstrated that the cellular uptake of smaller polystyrene particles $(50 \mathrm{~nm})$ by DCs was better than that of larger ones $(500 \mathrm{~nm})$ through intratracheal administration in mice, which resulted in more active lymphatic transport, improved maturation of DCs and production of cytokines. Furthermore, NPs with smaller particle size had a higher surface/volume ratio and were more likely to aggregate than larger ones. The aggregation of NPs not only affects their deposition in the lung and association with PS, but also changes the clearance mechanisms of NPs.

Shape. Shape is another important property that affects the interaction of NPs and cells, and the fate of NPs in the human body. Previous studies reported that spherical particles were more conducive to cellular internalization than shaped particles $(19,20)$. However, Gratton et al (21) reported that rod-shaped, cationic, cross-linked NPs modified with polyethylene glycol (PEG) were internalized at a higher rate than particles of other shapes (spheres, cylinders and cubes). In contrast, it was reported that gold nanospheres had better blood circulation and higher overall tumor accumulation rate than other shapes (nanodiscs, nanorods and nanocages) (22). Moreover, shape may also be involved in regulating the transport of NPs on the PS monolayer. A previous study revealed that NPs smaller than the thickness of the PS layer tended to be submerged and hardly transported through the PS layer, whereas NPs larger than the thickness of the lung surfactant layer tended to be encapsulated by the PS layer (23). The results of coarse-grained molecular dynamics simulations suggested that rod-like NPs exhibited stronger penetration and less adverse effects on the dipalmitoylphosphatidylcholine (DPPC) monolayer compared with other shapes $(24,25)$.

Surface charge. The surface charge of NPs determines the interaction between NPs and anionic cell membranes. Since positively charged NPs have the potential to induce damage to cell membranes and organelles, nanocarriers with stronger positive charges may not be an ideal choice for drug delivery systems (26). For example, Mousseau and Berret (27) observed a stronger interaction between positively charged NPs and PS compared with negatively charged NPs in vitro, which resulted in the aggregation of NPs and reduced their transfer efficiency.

However, in some specific fields, positively charged NPs have shown obvious advantages. A previous study in mice revealed that cationic NPs were mostly associated with DCs, whereas anionic particles were mainly internalized by alveolar macrophages (28). It is possible that the different cellular uptake mechanisms of cationic and anionic NPs might lead to different immune effects following pulmonary administration. Through animal experiments in mice, Tada et al (29) demonstrated that cationic liposomes induced higher antigen-specific antibody levels compared with anionic and neutral liposomes. Similarly, Fromen et al (30) reported that cationic NPs $(\sim 37 \mathrm{mV})$ conjugated with model antigen ovalbumin induced a higher level of antigen-specific $\operatorname{IgG}$ and local mucosal $\operatorname{IgA}$ in the plasma and bronchoalveolar lavage fluid (BALF) of mice after pulmonary immunization. In addition, cationic NPs could produce a large number of $\mathrm{CD}^{+} \mathrm{T}$ cells and a high level of chemokines or cytokines, whereas negatively charged counterparts $(\sim-38 \mathrm{mV})$ could not induce the same level of immunity response. Notably, positively charged cationic nanocarriers are widely used in drug delivery systems for gene therapy (31).

Wettability. The differences in wettability of NPs are often associated with different treatment outcomes. Hydrophobic 
NPs are deemed to interact more closely with the negatively charged cell membrane when compared with hydrophilic NPs. However, the hydrophobicity of NPs can mimic a danger signal to stimulate the immune system (32). Nanogels comprised of hydrophilic polymers [poly (sulfobetaine), PEG or poly (carboxybetaine)] were found to be effective in inhibiting immune responses after pulmonary administration, via a reduction in the degree of infiltration of inflammatory cells in the BALF and the expression of cytokines (TNF- $\alpha$ and IL-6) in a lipopolysaccharide (LPS)-induced inflammatory mouse model (33). Guzmán et al (34) reported that NPs incorporated into Langmuir monolayers of DPPC could alter the interfacial organization of the molecules. When compared with hydrophobic carbon black, hydrophilic silica had stronger influence on DPPC phase behavior.

Classification and advantages of NPs as drug delivery systems for treating respiratory diseases. NPs have great potential to be applied as pulmonary delivery systems for the diagnosis and treatment of local respiratory diseases and may even exert systemic actions, such as blood coagulation (35) and cardiovascular effects (36). Delivery of therapeutic drugs to target sites may be important for efficient treatment of tuberculosis, lung cancer, cystic fibrosis, and other acute and chronic respiratory infections. As early as 1654, an inhalation device was first designed by Bennet to produce opium vapor for cough treatment (37). The Food and Drug Administration (FDA) has already approved several materials as drug delivery systems, including liposomal, polymeric, dendrimers, inorganic and protein materials. More complex materials comprised of micelles, proteins, and a variety of inorganic or metallic materials are currently in development for assessment in clinical trials (38).

Liposomes. The application of liposomes as a drug delivery system has a significant impact on pharmacology. Liposomes are a class of lipid vesicles composed mainly of phospholipids and cholesterol. This colloidal form is comprised of a self-assembled lipid bilayer with amphiphilic domains, including an inner aqueous core and an outer shell of the lipid bilayer (39). According to the physical properties of the drug, liposomes can encapsulate drugs with different solubility in the water core or bilayer interface of the phospholipid bilayer, and enhance the solubility of the loaded drug through the co-solubility effect (37). The lipid bilayer of liposomes is similar to the composition of cell membranes in the body, which can not only reduce its toxicity, but can also enable liposomes to cross numerous biological barriers (40), thereby increasing absorption and ultimately enhancing the therapeutic effect of loaded drugs. In addition, liposomes can be used as carriers for other functional groups, such as targeted ligands, to create new properties for the delivery of therapeutic drugs (41). Furthermore, a previous study by Garbuzenko et al (42) tested a variety of nanomaterials to select the best inhalation carrier for anticancer drugs, and revealed that compared with non-lipid-based carriers, lipid-based nanocarriers had advantages in terms of accumulation and retention time in the lungs. Based on these advantages, liposomes became the earliest nanocarriers approved by the FDA in 1995, including liposome formulations of doxorubicin (DOX; Doxil $\left.{ }^{\circledR}\right)(43)$ and amphotericin B (44). In the past few decades, nanomedicine based on the liposome delivery system has generated the interest of scientists and clinicians in different fields of respiratory diseases (Table I). For example, in an orthotopic mouse model of human lung A549 non-small cell lung cancer (NSCLC) cells, Garbuzenko et al (45) compared the effects of intravenous and intratracheal administration of liposome-encapsulated DOX, antisense oligonucleotides and small interfering RNA (siRNA) on lung cancer, and demonstrated that compared with systemic administration by intravenous injection, intratracheal administration resulted in much higher peak concentrations and longer retention time of three drugs in the lungs, which indicated that local intratracheal administration was better than systemic administration of the same drug. Similarly, Koshkina et al (46) proved that the pulmonary delivery of paclitaxel (PTX) in liposome aerosol formulations was more efficient than intravenous injection in mice. In a carbamate-induced lung tumor mouse model, Fritz et al (47) showed that clodronate encapsulated with liposomes reduced the number of macrophages by $50 \%$ after 4-6 weeks of treatment and significantly weakened the proliferative ability of tumor cells. Besides, a phase I clinical trial carried out by Wittgen et al (48) explored the application of cisplatin liposomal formulation in lung cancer. Their results indicated that this drug delivery system could enhance the drug accumulation and reduce the systemic side effects.

Several types of antimicrobials for the treatment of airway infections can also be delivered by liposomes. A double-blind, randomized, phase II clinical trial conducted by Olivier et al (49) applied inhaled liposomal amikacin in the treatment of nontuberculous mycobacterial lung disease; the results revealed that the drug promoted the negative conversion of sputum and induced lower toxicity compared with parenteral amikacin. Similarly, Zhang et al (50) explored the efficacy of liposomal amikacin in nontuberculous mycobacteria both in vivo (rat model) and in vitro, and their results showed that this nanodrug could effectively enter bacterial biofilms, improve cellular uptake of amikacin in macrophages and inhibit the distribution of amikacin to other tissues. Additionally, through a randomized controlled clinical trial, Okusanya et al (51) reported that liposomal amikacin improved lung function and reduced bacterial density in the lung of patients with chronic Pseudomonas infection.

Furthermore, liposomal drug delivery systems have been applied to inflammatory respiratory diseases. For example, Konduri et al (52) investigated the effect of liposomal budesonide on the treatment of asthma using a mouse model; the results revealed that this drug delivery system significantly improved lung inflammation and reduced the toxicity of inhaled steroid asthma drugs. Chen et al (53) designed liposomes to encapsulate salbutamol sulfate (SBS) in aerosol form and demonstrated that the complexes exhibited longer anti-asthmatic effects than free SBS. Furthermore, Ng et al (54) demonstrated that liposome-encapsulated curcumin exerted an inhibitory effect on LPS-induced airway inflammation via cell experiments in vitro. A recent study performed by Komalla et al (55) through cell and animal experiments found that empty liposomes (UTS-001) could be used to treat chronic respiratory diseases by inhibiting epithelial pro-inflammatory cytokines and reducing the number of eosinophils. 


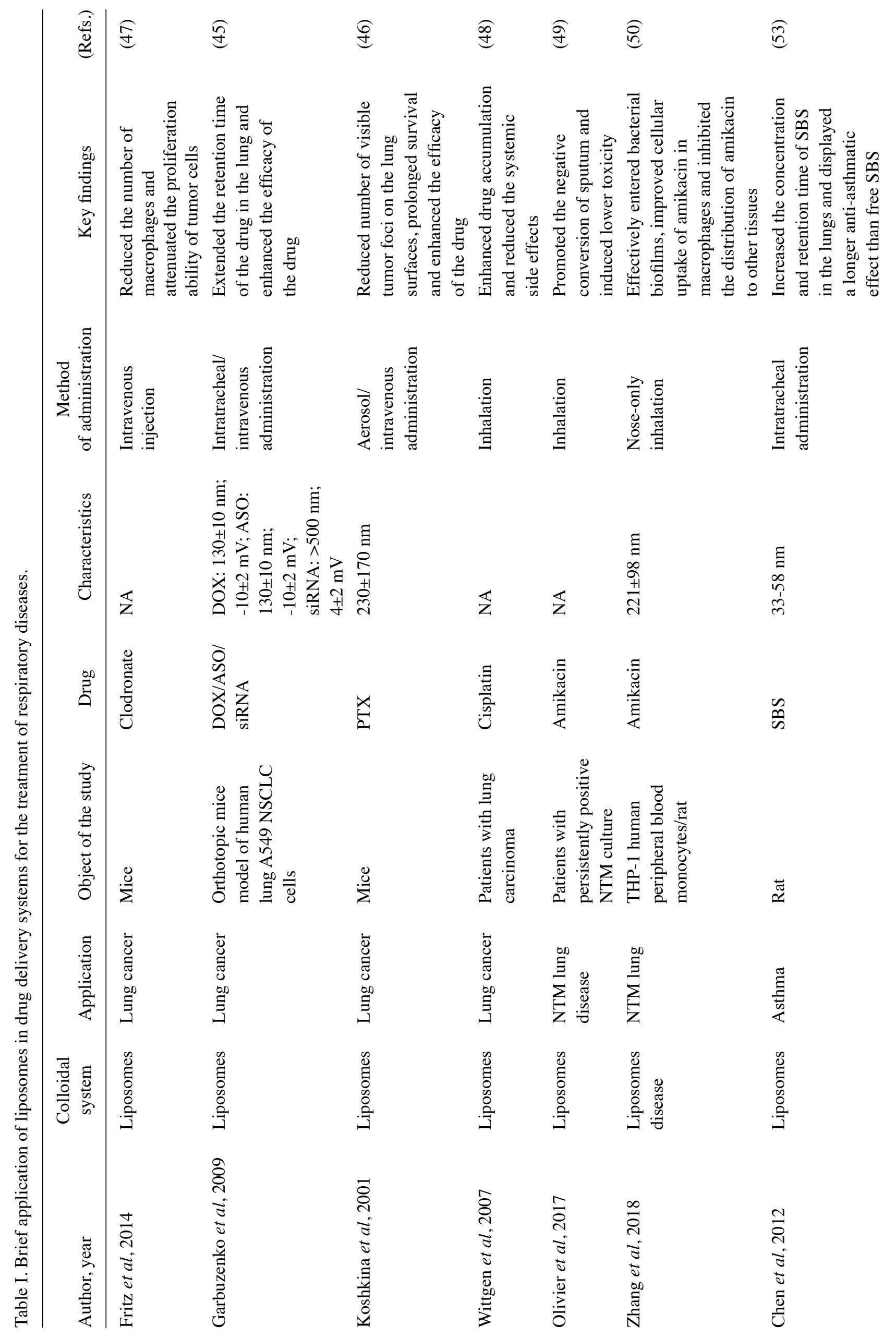




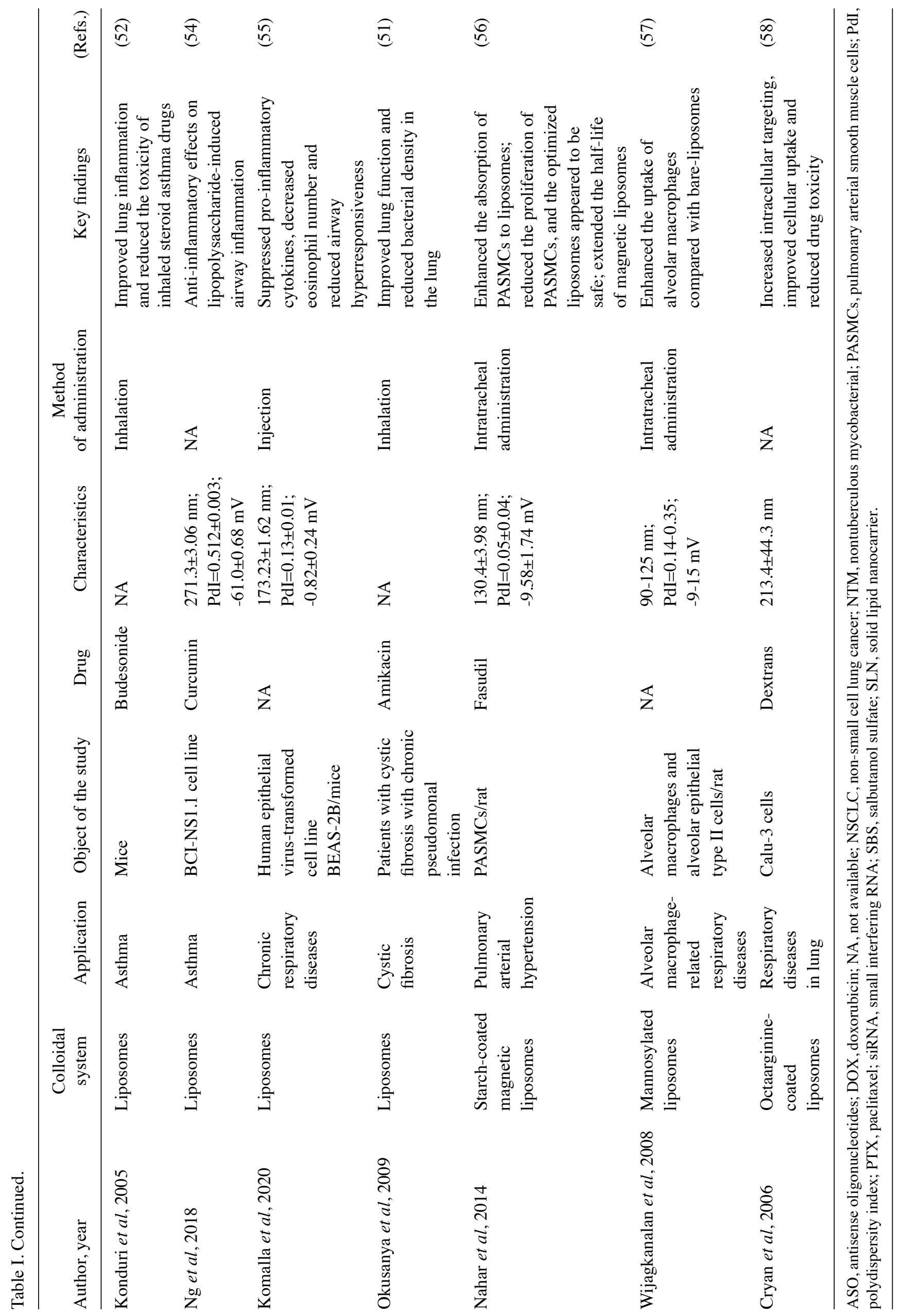


In addition to simple liposomal nanocarriers, numerous groups have successfully modified liposomes to improve their properties, including cellular uptake, stability and targeting. For example, Nahar et al (56) demonstrated that starch-coated magnetic liposomes could be used as an inhalable carrier to deliver fasudil to treat pulmonary hypertension through in vitro cell experiments and rat animal models. In addition, a previous study reported that the cellular uptake of mannosylated liposomes by alveolar macrophages was higher compared with that of non-modified ones after intratracheal administration both in vivo and in vitro (57). Through in vitro experiments, Cryan et al (58) showed that octaarginine-coated liposomes could increase intracellular targeting, improve cellular uptake and reduce drug toxicity in airway cells.

Solid lipid nanocarriers (SLNS). SLNs are another type of lipid-based material, which are slightly different from liposomes in structure. SLNs may represent an alternative to traditional carrier systems due to their numerous advantages, including targeted drug delivery, controlled-release, high drug stability, high drug loading, encapsulation of hydrophilic and lipophilic drugs, low carrier toxicity, avoidance of organic solvents in production (such as high-pressure homogenization) and large-scale industrial production $(59,60)$. Nassimi et al $(61)$ evaluated the toxicity of SLNs as potential nanocarriers in in vitro and ex vivo lung models, and their results showed that SLN20 (20\% phospholipids included in particle lipid matrix) could be used as a safe pulmonary drug delivery system.

In the past few years, as a colloidal drug delivery system, SLNs have promoted the development of the treatment of respiratory diseases (Table II). For example, Videira et al (62) investigated the antitumor effect of PTX-loaded SLNs on lung cancer, and revealed that the pulmonary delivered nanodrug efficiently reduced cellular toxicity and suppressed the progression of lung metastases in vitro and in vivo. In addition, Castellani et al (63) designed SLN-encapsulated grape seed-derived proanthocyanidins to treat chronic respiratory diseases, and confirmed that the complex could inhibit oxidative stress and inflammation in airway epithelial cells through cell experiments and mouse models.

Moreover, SLNs can be modified to improve their targeting ability, thereby increasing the accumulation of drugs in targeted sites and reducing systemic toxicity. For the treatment of tuberculosis (64), Maretti et al (65) used SLN modified with mannose derivatives as nanocarriers of rifampicin, and tested the anti-tuberculosis ability of the novel drug in J774 murine macrophage cells. Their results showed that SLNs modified with the surfactants (mannose derivatives) could improve the absorption capacity of macrophages for their encapsulated drugs. A similar study was carried out by Nimje et al (66), which revealed that mannose-conjugated SLNs could deliver rifampicin more effectively than bare-SLNs, which increased the therapeutic effect and reduced the side effects of the drug.

Polymeric nanocarriers. A polymer is a type of large molecule chemical compound, which is composed of numerous smaller homogeneous molecules. Polymers can be natural (albumin, gelatin, alginate, collagen, cyclodextrin and chitosan) or synthetic [poly-lactic-co-glycolic acid (PLGA), polyacrylates, polyethyleneimine (PEI), PEG, polyanhydrides and poly-l-lysine] (67). Polymers with particular biological and physicochemical advantages are used for the formulation of nanocarriers to deliver therapeutic and diagnostic drugs. Polymer-based nanocarriers can deliver different agents, which are inserted into the surface of the polymer or dispersed in the polymeric matrix (68).

Aliphatic polyesters are the most commonly used polymer nanocarriers due to their excellent biocompatibility, controlled-release properties and sufficient biodegradability under physiological conditions (69). Various forms of polymeric nanocarriers have been used in preclinical experiments for the treatment of respiratory diseases (Table III). Among them, PLGA has been approved by the FDA for use as a drug delivery system. Türeli et al (70) prepared PLGA NPs loaded with ciprofloxacin and tested their therapeutic effects on bacterial infection-induced cystic fibrosis in Calu-3 and CFBE410 cells. The results showed that the nanomedicine had high drug loading and permeability, which could not only achieve high and persistent local drug concentration, but also decrease the drug dose to reduce side effects. Through in vitro and in vivo experiments, Kim et al (71) revealed that the sustained-release inhalation system assembled by DOX and PLGA had high encapsulation efficiency and good nebulization ability, could effectively inhibit the growth of tumor cells and was suitable for the treatment of metastatic lung cancer. A previous study in guinea pigs performed by Pandey et al (72) showed that the encapsulation of PLGA prolonged the elimination half-life and average residence time of three anti-tuberculosis drugs, thereby increasing the bioavailability and reducing the frequency of administration. Besides, Tomoda et al (73) demonstrated that PLGA NPs loaded with TAS-103 enhanced drug toxicity to A549 lung cancer cells and increased the drug concentration in the lungs of rats. For gene transfer applications in the treatment of respiratory disease, PLGA is also considered a good choice. An in vitro study by Zou et al (74) reported that negatively charged bioadhesive PLGA NPs could be used as an efficient non-viral vector for gene therapy in the treatment of lung cancer.

Although PLGA has numerous advantages, it also has several limitations as a pulmonary delivery system. For example, the slow degradation rate of PLGA may result in excessive accumulation of PLGA in the respiratory tract (75). The degradation rate of the drug depends on the composition and molecular weight of polymeric nanocarriers, and the release period varies from several weeks to several months. Moreover, continuous hydrolysis of PLGA may generate an acidic core within the drug delivery device, which lowers the $\mathrm{pH}$ of the microenvironment and damages $\mathrm{pH}$-sensitive encapsulated proteins, such as peptides and proteins (76). Additionally, due to the extreme hydrophobicity of PLGA, the encapsulation efficiency of low-molecular-weight hydrophilic drugs may be undesirably low and the hydrophobic surface may cause rapid protein adsorption, leading to the clearance of PLGA by alveolar phagocytes (77).

Solutions have been applied to optimize the design and overcome the problems of PLGA delivery devices. To overcome the accumulation of PLGA carriers, several polymers with faster degradation rates have been synthesized for drug delivery. Polybutylcyanoacrylate (PBCA) is a noncytotoxic and biodegradable NP that can be used for pulmonary 


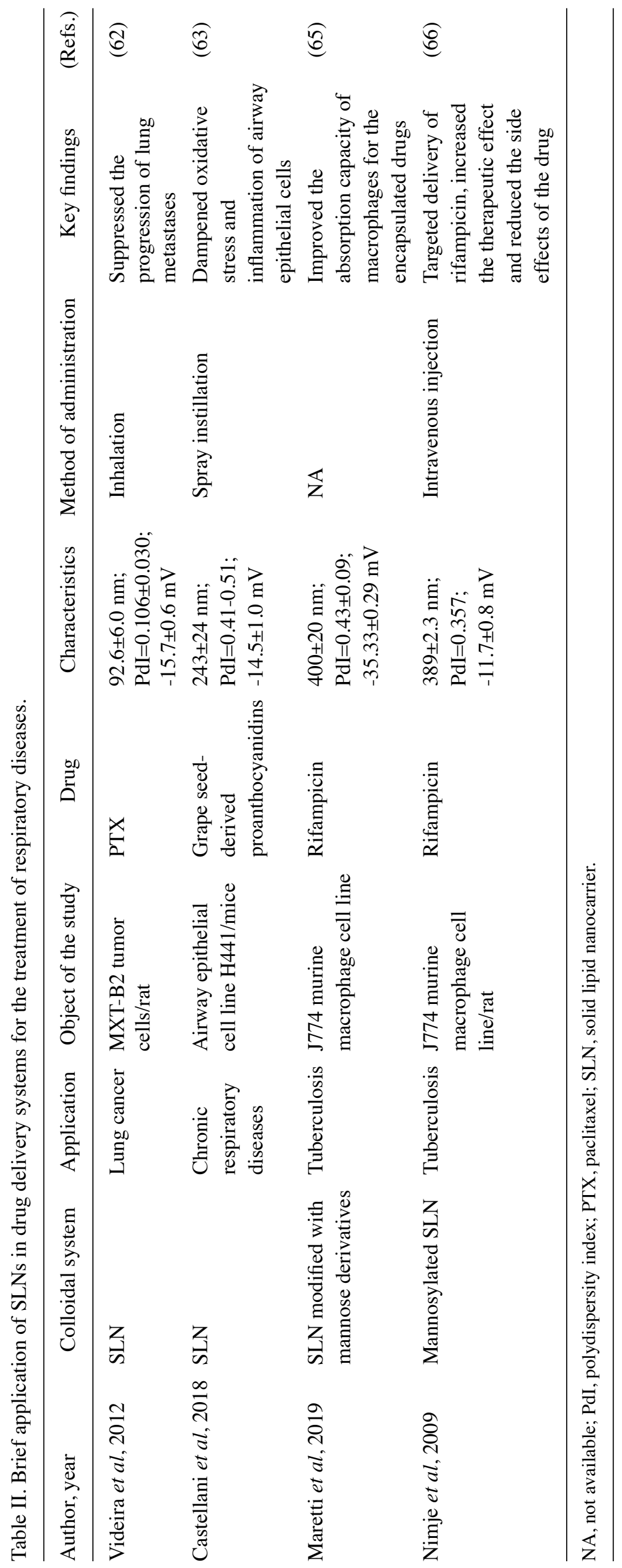




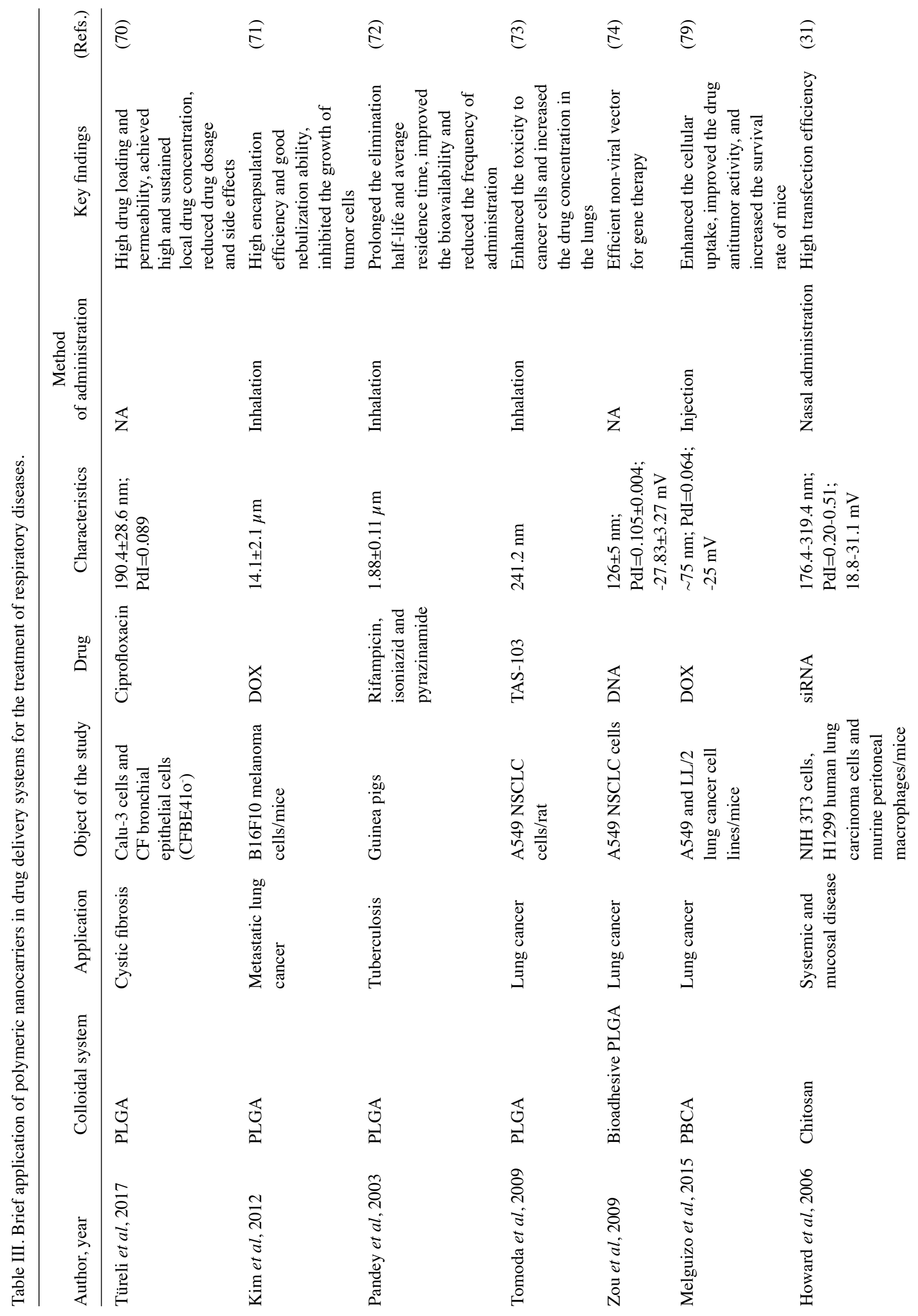


administration; in addition, it is $\mathrm{pH}$-sensitive and can be catalyzed by enzymes (78). Compared with free DOX, in vitro and in vivo studies by Melguizo et al (79) revealed that PBCA-encapsulated DOX significantly enhanced the drug uptake of lung cancer cells, improved the antitumor activity of drugs and increased the survival rate of mice. Another approach is to use hydrophilic polymers to reduce accumulation of polymerics in the body. For stabilization of proteins within PLGA, pH-sensitive drugs could be pre-mixed with zinc or antacid excipients could be added to buffer the vehicle microclimate (80).

Polymers are important delivery carriers for nano-gene drugs in gene therapy of respiratory diseases; as well as the aforementioned modified PLGA, PEI is also a promising polymer for delivering recombinant genes to mammalian cells due to its high transfection efficiency, biocompatibility and biodegradability $(81,82)$. This polymer with positively charged groups is able to closely interact with negatively charged genes. Similarly, chitosan is another nanocarrier commonly used in gene therapy for drug delivery. It is positively charged under neutral and acidic $\mathrm{pH}$ conditions and is a biodegradable polymer synthesized through the deacetylation of chitin (83). In 2006, Howard et al (31) synthesized a NP system composed of siRNA and chitosan, and revealed that the complex had high transfection efficiency in vitro and in vivo, and it was considered a potential genetic medicine for mucosal disease. Beyond that, in order to improve the transfection efficiency of gene drugs, a variety of improved polymer carriers based on chitosan have been proposed. Germershaus et al (84) compared the performance of chitosan, trimethyl chitosan and PEGylated trimethyl chitosan as DNA carriers, and the results showed that compared with unmodified chitosan, both modified forms of chitosan exhibited improved cellular uptake and transfection efficiency. In addition, the quaternization of chitosan could effectively inhibit the $\mathrm{pH}$ dependence and aggregation of DNA complexes, and PEGylation could further improve the stability of colloids.

Dendrimers. A dendrimer is a type of polymer nanostructure that is different from traditional polymers. It has a highly branched monodisperse three-dimensional structure. The multiple functional groups distributed on the surface of a dendrimer increase its versatility and biocompatibility as a nanocarrier (85). In addition, their external functional groups can be modified by other charged compounds through electrostatic interaction, and dendrimers with both hydrophobic and hydrophilic group structures can deliver a large number of drug molecules with different solubility (86). During the delivery process, the loaded drug can be combined with the functional groups on the surface of the dendrimer, or it can be wrapped in the molecular cavity of the dendrimer (87).

Based on these advantages, dendrimers have attracted the attention of researchers in the field of drug delivery due to their unique structural and physicochemical properties (Table IV). For example, a previous in vitro study by Bellini et al (88) reported that fourth-generation polyamidoamide (G4-PAMAM) dendrimers containing the anti-tuberculosis drug rifampicin had high stability under physiological $\mathrm{pH}$ conditions, and the PAMAM dendrimers could be used as a $\mathrm{pH}$ switch to rapidly release drugs in the acidic area of 


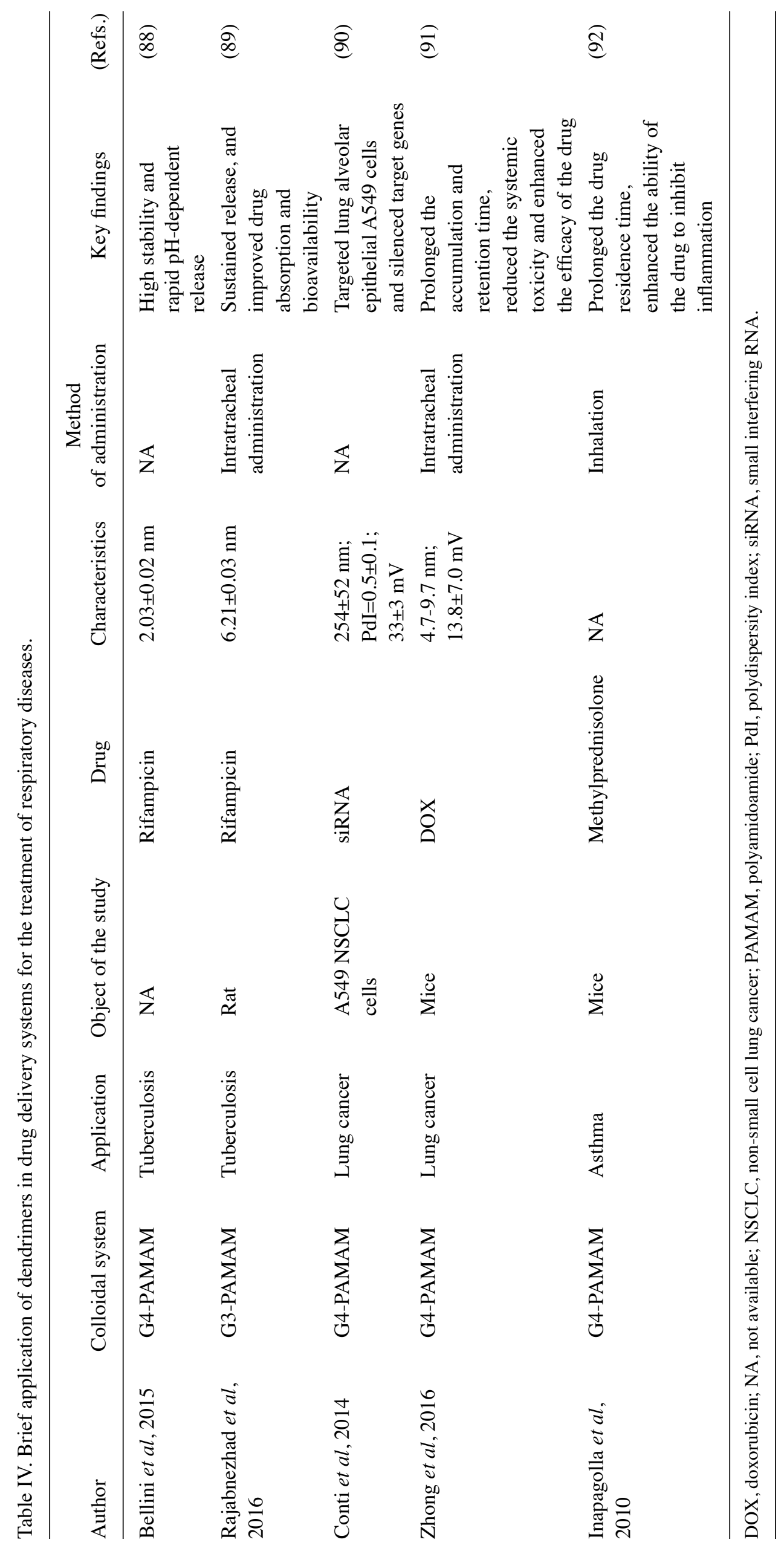


macrophages. Similarly, Rajabnezhad et al (89) synthesized different generations of PAMAM dendrimers encapsulating rifampicin to produce inhalable nanodrugs for the treatment of tuberculosis. Their results showed that compared with intravenous administration, third generation PAMAM dendrimers achieved sustained drug release, and significantly improved drug absorption and bioavailability. For the application of dendrimers in lung cancer, Conti et al (90) used an amine-terminated G4-PAMAM dendrimer (G4NH2) loaded with siRNA to decrease the expression of enhanced green fluorescent protein in a model of A549 cells, indicating that G4NH2-siRNA could not only target alveolar epithelial cells, but could also effectively silence the target gene. Furthermore, Zhong et al (91) explored the effect of a complex composed of DOX and carboxyl-terminated G4-PAMAM dendrimers in lung metastasis, and confirmed that compared with intravenous administration, the complex prolonged the accumulation and retention time of the drug in the lung and reduced systemic toxicity, thereby enhancing the efficacy of DOX on melanoma lung metastasis and increasing the survival rate of mice. In addition, dendrimers have been used to treat inflammatory respiratory diseases related to asthma. Through a mouse lung inflammation model, Inapagolla et al (92) revealed that G4-PAMAM conjugated with methylprednisolone (MP) might enhance the ability of MP to inhibit inflammation by prolonging the residence time of the drug within the lung.

Inorganic nanocarriers. There are several types of inorganic substances that have been used to synthesize NPs, including gold, silica, iron oxide, alumina and titanium dioxide. Inorganic NP carriers possess several advantages, such as high biocompatibility, high delivery efficiency, high stability, magnetic properties and resistance to microbial degradation (93). Several iron oxide NPs have been approved by the European Union. Based on the plasmonic and magnetic characteristics of inorganic materials, they can also be used for diagnosis of respiratory diseases, such as positron emission tomography, computed tomography and magnetic resonance imaging (94). The external magnetic field can not only direct these magnetic NPs to the targeted sites, but also increase the temperature of these NPs (95). High temperature can induce apoptosis of target cells, including infected cells and cancer cells $(86,96)$.

In addition to high-temperature-based targeted drug control, gold NPs (AuNPs), as typical inorganic NPs, are often used as nanocarriers in drug delivery systems for the treatment of respiratory diseases (Table V). For example, a previous study conducted by Chen et al (97) demonstrated that methotrexate (MTX)-AuNPs were more cytotoxic to tumor cell lines than free MTX, and MTX could inhibit tumor growth only when under AuNP encapsulation both in vitro and in vivo. Similarly, Brown et al (98) confirmed that AuNPs increased the toxicity of the antitumor drug oxaliplatin to lung cancer cell lines. Apart from the application in lung cancer treatment, Codullo et al (99) investigated the role of AuNP-loaded imatinib in the treatment of lung fibrosis through cell experiments and mouse models, and the results showed that the complex could significantly improve the anti-fibrotic efficacy of imatinib, thereby inhibiting the proliferation of fibroblasts and macrophages.
Despite these advantages, drug delivery systems using metal NPs as carriers still have some limitations. For example, when administered by intravenous injection, positively charged AuNPs are easily combined with negatively charged serum proteins in the blood and form aggregates (96). Based on this defect, previous studies have proposed an improved solution, that is, PEG modification of the surface to prevent the aggregation of AuNPs and thus improve their stability during storage (100). Omlor et al (101) modified AuNPs with PEG and citrate to reduce airway inflammation in a mouse model. Furthermore, an in vitro study performed by Park et al (102) combined cell-penetrating peptides with PEG-AuNPs to enhance the cell death-inducing activity of the anticancer drug DOX. In addition, the potential concentration-dependent cytotoxicity and low excretion of inorganic nanocarriers also limit their clinical application to a certain extent. Therefore, systemic absorption and subsequent adverse events must be fully considered when designing and examining nanomedicine.

Protein nanocarriers. Protein NPs include a large number of classes, such as endogenous protein carriers conjugated with drugs, engineered proteins and combined platforms that rely on protein or peptide motifs for targeting delivery (103). Protein NPs have many advantages, including high biocompatibility and solubility, biodegradability, modifiability, controlled-release properties and targeted drug delivery (104). At present, a large number of preclinical experiments based on protein nanocarriers have been reported in the field of respiratory diseases, particularly for respiratory infection (Table VI). Among them are virus-like particles (VLPs), which are a type of protein NP assembled from viral proteins with diverse structures and functions (Table VI). The proteins of VLPs can be commercially expressed in numerous systems, such as prokaryotic systems (Escherichia coli) and eukaryotic systems (yeast and insect cells) (105). VLPs could be used as nanocarriers for vaccines to treat infectious respiratory diseases, such as influenza virus and respiratory syncytial virus (RSV) infection (106). For example, Coleman et al (107) proposed to use purified coronavirus spike protein NPs to load Middle East respiratory syndrome coronavirus (MERS-CoV) and severe acute respiratory syndrome coronavirus (SARS-CoV) protein antigens for vaccination. The results showed that this strategy could produce high titers of antibodies in mouse models. Additionally, Smith et al (108) and Lee et al (109) used baculovirus vector and VLPs to combine with RSV fusion proteins to construct protein nanocarrier vaccines, respectively. The results demonstrated that in cotton rat and mouse models RSV replication was effectively inhibited in the lungs following intramuscular injection of vaccines, and nanocarriers promoted the immunogenicity of vaccines when compared with traditional formalin-inactivated RSV. In addition to the application of vaccination strategies, protein nanocarriers have been used in other respiratory diseases. A previous in vitro study confirmed that the encapsulation of apigenin with bovine serum albumin could inhibit lung injury induced by immune responses by enhancing antioxidant activity (110).

The advantages and limitations of therapeutic nanomedicine in respiratory diseases. Inhaled administration is a non-invasive drug delivery route. The drug is delivered through 


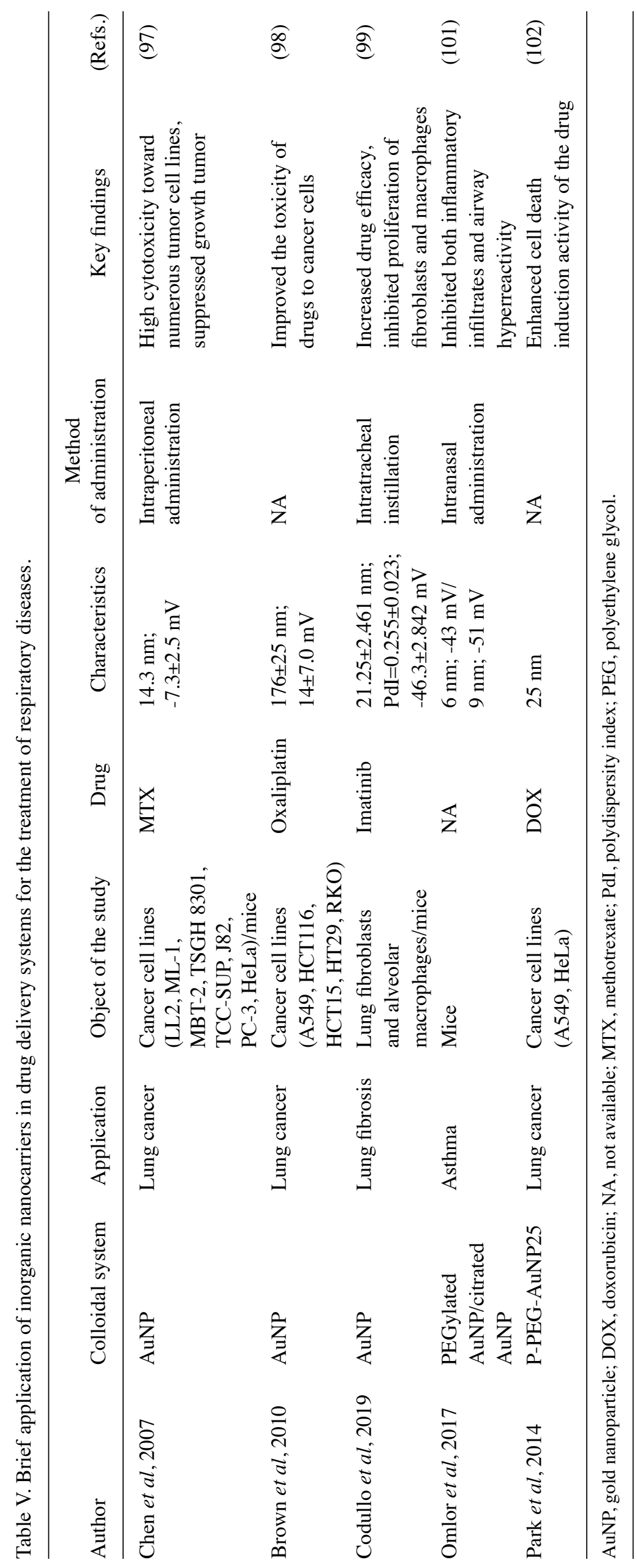


the cavity of the respiratory tract and the mucous membrane to achieve local or systemic drug delivery. The special physiological structure of the lung determines the characteristics and advantages of inhaled administration. Firstly, pulmonary inhalation can achieve effective lung-targeted medication and maintain the biological activity of the drug, which is suitable for the treatment of common respiratory diseases, including asthma, emphysema and chronic bronchitis (111). Secondly, in contrast to other routes of administration, such as oral and intramuscular injection, pulmonary inhalation takes effect rapidly (112). Thirdly, pulmonary inhalation can avoid hepatic first-pass metabolism, decrease the dosage of administration and reduce systemic side effects (113).

Based on the basic advantages of pulmonary inhalation, the application of nanotechnology in drug delivery systems has further improved the efficacy of inhalation therapy for different respiratory diseases. In general, nanocarriers enhance cellular uptake and achieve therapeutic effects in the lungs with lower drug doses (70), enhance the solubility of drugs, particularly the delivery of hydrophobic molecules $(37,86)$, enhance the stability of drugs under physiological conditions (88), achieve controlled-release to prevent the rapid elimination of drugs $(72,91,92)$ and result in targeted drug delivery $(57,66,90)$.

Although nanocarriers have promoted the development of drugs related to respiratory diseases, the potential toxicity of NPs to the lung microenvironment or systemic toxicity is also the focus of current nanomedicine research. It has been reported that the size, surface charge, polarity and degradability of NPs are typical characteristics related to toxicity (114). Previous studies have demonstrated that inhalation of nanomaterials $<100 \mathrm{~nm}$ is usually related to chronic toxicity $(115,116)$. Therefore, in terms of particle size, the drug development process needs to fully balance the efficacy and toxicity of the nanodrug. However, a previous study evaluated the effects of particles with different sizes $(50-150 \mathrm{~nm})$ and different materials (PEG-ylated lipid particles, polyvinyl acetate and polystyrene) on mice, and found that acute respiratory toxicity was independent of particle size and only hydrophobic materials caused inflammation (117). In addition, Dailey et al (118) compared non-biodegradable polymers and biodegradable polymers of the same size, and confirmed that NPs derived from biodegradable polymers produced less toxicity and inflammatory responses. Furthermore, the application of nanocarriers in pharmaceutical preparations may change the distribution behavior of the original drugs in the body, which may cause new unpredictable adverse reactions.

Briefly, in the process of developing nanomedicine for the treatment of respiratory diseases, it is necessary to systematically explore the interaction between the nanomedicine and the respiratory system, including in vitro and in vivo detection methods to measure the genotoxicity, cytotoxicity and tissue toxicity of the drug (119), in order to thoroughly examine the safety, tolerability and therapeutic effect of NPs in treatment. Although some preclinical studies have shown promising application prospects, the current clinical trials of nanomedicine related to respiratory diseases remain limited, and the clinically known applications of nanocarriers are liposomes $(48,49)$ in nontuberculous mycobacterial lung disease and lung cancer, and PLGA in pulmonary arterial hypertension (120). 


\section{Conclusions}

Nanotechnology has become an important tool to overcome the defects of drugs, and to enable them to target specific cells or tissues passively or actively. The present review summarized the applications and advantages of NPs as drug delivery vehicles in respiratory diseases, such as lung cancer, asthma, chronic respiratory diseases, cystic fibrosis, tuberculosis and respiratory infection. The combination of nanotechnology has further promoted the development of drugs for respiratory diseases based on the benefits of inhaled administration. However, although preclinical studies have shown broad development prospects, most relevant studies are still in the early stage of experimentation, and their clinical effects need to be further verified. Future studies should focus on the performance modification, molecular mechanism and potential toxicity of therapeutic nanomedicine in the process of treatment.

\section{Acknowledgements}

Not applicable.

\section{Funding}

No funding was received.

\section{Availability of data and materials}

Not applicable.

\section{Authors' contributions}

MXL wrote and revised the manuscript. SH contributed to the conception and design of the work. QYS contributed to the drafting of the article and literature search. MXL and QYS confirmed the authenticity of all the raw data. All authors read and approved the final manuscript.

\section{Ethics approval and consent to participate}

Not applicable.

\section{Patient consent for publication}

Not applicable.

\section{Competing interests}

The authors declare that they have no competing interests.

\section{References}

1. D'Amato G and Cecchi L: Effects of climate change on environmental factors in respiratory allergic diseases. Clin Exp Allergy 38: 1264-1274, 2008.

2. Ferkol T and Schraufnagel D: The global burden of respiratory disease. Ann Am Thorac Soc 11: 404-406, 2014.

3. Newman SP: Delivering drugs to the lungs: The history of repurposing in the treatment of respiratory diseases. Adv Drug Deliv Rev 133: 5-18, 2018.

4. Chang LH and Rivera MP: Respiratory diseases: Meeting the challenges of screening, prevention, and treatment. N C Med J 74: 385-392, 2013.
5. Jeong J, Lee S, Kim SH, Han Y, Lee DK, Yang JY, Jeong J, Roh C, Huh YS and Cho WS: Evaluation of the dose metric for acute lung inflammogenicity of fast-dissolving metal oxide nanoparticles. Nanotoxicology 10: 1448-1457, 2016.

6. Pison U, Welte T, Giersig M and Groneberg DA: Nanomedicine for respiratory diseases. Eur J Pharmacol 533: 341-350, 2006.

7. Fröhlich E and Salar-Behzadi S: Toxicological assessment of inhaled nanoparticles: Role of in vivo, ex vivo, in vitro, and in silico studies. Int J Mol Sci 15: 4795-4822, 2014.

8. Sung JC, Pulliam BL and Edwards DA: Nanoparticles for drug delivery to the lungs. Trends Biotechnol 25: 563-570, 2007.

9. Bakand S, Hayes A and Dechsakulthorn F: Nanoparticles: A review of particle toxicology following inhalation exposure. Inhal Toxicol 24: 125-135, 2012.

10. Donaldson K, Tran L, Jimenez LA, Duffin R, Newby DE, Mills N, MacNee W and Stone V: Combustion-derived nanoparticles: A review of their toxicology following inhalation exposure. Part Fibre Toxicol 2: 10, 2005.

11. Xu Y, Li S, Luo Z, Ren H, Zhang X, Huang F, Zuo YY and Yue T: Role of lipid coating in the transport of nanodroplets across the pulmonary surfactant layer revealed by molecular dynamics simulations. Langmuir 34: 9054-9063, 2018.

12. Auria-Soro C, Nesma T, Juanes-Velasco P, Landeira-Viñuela A, Fidalgo-Gomez H, Acebes-Fernandez V, Gongora R, Parra MJA, Manzano-Roman R and Fuentes M: Interactions of nanoparticles and biosystems: Microenvironment of nanoparticles and biomolecules in nanomedicine. Nanomaterials (Basel) 9: 1365, 2019.

13. Senapati S, Mahanta AK, Kumar S and Maiti P: Controlled drug delivery vehicles for cancer treatment and their performance. Signal Transduct Target Ther 3: 7, 2018.

14. Poh TY, Mohamed Ali NAB, Aogáin MM, Kathawala MH, Setyawati MI, Ng KW and Chotirmall SH: Inhaled nanomaterials and the respiratory microbiome: Clinical, immunological and toxicological perspectives. Part Fibre Toxicol 15: 46, 2018.

15. Oberdorster G, Elder A, and Rinderknecht A: Nanoparticles and the brain: Cause for concern? J Nanosci Nanotechnol 9: 4996-5007, 2009.

16. Murgia X, Pawelzyk P, Schaefer UF, Wagner C, Willenbacher N and Lehr CM: Size-Limited penetration of nanoparticles into porcine respiratory mucus after aerosol deposition. Biomacromolecules 17: 1536-1542, 2016.

17. Blank F, Stumbles PA, Seydoux E, Holt PG, Fink A, Rothen-Rutishauser B, Strickland DH and von Garnier C: Size-Dependent uptake of particles by pulmonary antigen-presenting cell populations and trafficking to regional lymph nodes. Am J Respir Cell Mol Biol 49: 67-77, 2013.

18. Ghaffar KA, Marasini N, Giddam AK, Batzloff MR, Good MF, Skwarczynski $\mathrm{M}$ and Toth I: The role of size in development of mucosal liposome-lipopeptide vaccine candidates against group a streptococcus. Med Chem 13: 22-27, 2016.

19. Murugan K, Choonara YE, Kumar P, Bijukumar D, du Toit LC and Pillay V: Parameters and characteristics governing cellular internalization and trans-barrier trafficking of nanostructures. Int J Nanomedicine 10: 2191-2206, 2015.

20. Zhang L, Wang Y, Yang D, Huang W, Hao P, Feng S, Appelhans D, Zhang T and Zan X: Shape effect of nanoparticles on tumor penetration in monolayers versus spheroids. Mol Pharm 16: 2902-2911, 2019.

21. Gratton SE, Ropp PA, Pohlhaus PD, Luft JC, Madden VJ, Napier ME and DeSimone JM: The effect of particle design on cellular internalization pathways. Proc Natl Acad Sci USA 105: 11613-11618, 2008

22. Black KC, Wang Y, Luehmann HP, Cai X, Xing W, Pang B, Zhao Y, Cutler CS, Wang LV, Liu Y and Xia Y: Radioactive 198Au-doped nanostructures with different shapes for in vivo analyses of their biodistribution, tumor uptake, and intratumoral distribution. ACS Nano 8: 4385-4394, 2014.

23. Hu G, Jiao B, Shi X, Valle RP, Fan Q and Zuo YY: Physicochemical properties of nanoparticles regulate translocation across pulmonary surfactant monolayer and formation of lipoprotein corona. ACS Nano 7: 10525-10533, 2013.

24. Lin X, Zuo YY and Gu N: Shape affects the interactions of nanoparticles with pulmonary surfactant. Sci China Mater 58: 28-37, 2015.

25. Beck-Broichsitter M, Ruppert C, Schmehl T, Günther A and SeegerW: Biophysical inhibition of synthetic vs. Naturally-Derived pulmonary surfactant preparations by polymeric nanoparticles. Biochim Biophys Acta 1838: 474-481, 2014.

26. Li J: Development of a QTsome lipid nanoparticle delivery platform for oligonucleotide therapeutics. The Ohio State University 2018. 
27. Mousseau F and Berret JF: The role of surface charge in the interaction of nanoparticles with model pulmonary surfactants. Soft Matter 14: 5764-5774, 2018.

28. Fromen CA, Rahhal TB, Robbins GR, Kai MP, Shen TW, Luft JC and DeSimone JM: Nanoparticle surface charge impacts distribution, uptake and lymph node trafficking by pulmonary antigen-presenting cells. Nanomedicine 12: 677-687, 2016.

29. Tada R, Hidaka A, Kiyono H, Kunisawa J and Aramaki Y Intranasal administration of cationic liposomes enhanced granulocyte-macrophage colony-stimulating factor expression and this expression is dispensable for mucosal adjuvant activity. BMC Res Notes 11: 472, 2018.

30. Fromen CA, Robbins GR, Shen TW, Kai MP, Ting JP and DeSimone JM: Controlled analysis of nanoparticle charge on mucosal and systemic antibody responses following pulmonary immunization. Proc Natl Acad Sci U S A 112: 488-493, 2015.

31. Howard KA, Rahbek UL, Liu X, Damgaard CK, Glud SZ, Andersen MØ, Hovgaard MB, Schmitz A, Nyengaard JR, Besenbacher $F$ and Kjems J: RNA interference in vitro and in vivo using a novel chitosan/siRNA nanoparticle system. Mol Ther 14: 476-484, 2006.

32. Fadeel B: Clear and present danger? Engineered nanoparticles and the immune system. Swiss Med Wkly 142: w13609, 2012.

33. Li B, Xie J, Yuan Z, Jain P, Lin X, Wu K and Jiang S: Mitigation of inflammatory immune responses with hydrophilic nanoparticles. Angew Chem Int Ed Engl 57: 4527-4531, 2018.

34. Guzmán E, Ferrari M, Santini E, Liggieri L and Ravera F: Effect of silica nanoparticles on the interfacial properties of a canonical lipid mixture. Colloids Surf B Biointerfaces 136: 971-980, 2015.

35. Borm PJ and Kreyling W: Toxicological hazards of inhaled nanoparticles-potential implications for drug delivery. J Nanosci Nanotechnol 4: 521-531, 2004.

36. Oberdörster G, Oberdörster E and Oberdörster J: Nanotoxicology: An emerging discipline evolving from studies of ultrafine particles. Environ Health Perspect 113: 823-839, 2005.

37. Ngan CL and Asmawi AA: Lipid-Based pulmonary delivery system: A review and future considerations of formulation strategies and limitations. Drug Deliv Transl Res 8: 1527-1544, 2018.

38. PatraJK,Das G,FracetoLF,CamposEVR,Rodriguez-TorresMDP, Acosta-Torres LS, Diaz-Torres LA, Grillo R, Swamy MK, Sharma S, et al: Nano based drug delivery systems: Recent developments and future prospects. J Nanobiotechnology 16: 71, 2018

39. Bulbake U, Doppalapudi S, Kommineni N and Khan W: Liposomal formulations in clinical use: An updated review. Pharmaceutics 9: 12, 2017.

40. Rudokas M, Najlah M, Alhnan MA and Elhissi A: Liposome delivery systems for inhalation: A critical review highlighting formulation issues and anticancer applications. Med Princ Pract 25: 60-72, 2016

41. Riaz MK, Riaz MA, Zhang X, Lin C, Wong KH, Chen X, Zhang G, Lu A and Yang Z: Surface functionalization and targeting strategies of liposomes in solid tumor therapy: A Review. Int J Mol Sci 19: 195, 2018.

42. Garbuzenko OB, Mainelis G, Taratula O and Minko T: Inhalation treatment of lung cancer: The influence of composition, size and shape of nanocarriers on their lung accumulation and retention. Cancer Biol Med 11: 44-55, 2014.

43. Barenholz Y: Doxil®-the first FDA-approved nano-drug: lessons learned. J Control Release 160: 117-134, 2012.

44. Rust DM and Jameson G: The novel lipid delivery system of amphotericin B: Drug profile and relevance to clinical practice. Oncol Nurs Forum 25: 35-48, 1998.

45. Garbuzenko OB, Saad M, Betigeri S, Zhang M, Vetcher AA, Soldatenkov VA, Reimer DC, Pozharov VP and Minko T: Intratracheal versus intravenous liposomal delivery of siRNA, antisense oligonucleotides and anticancer drug. Pharm Res 26: 382-394, 2009

46. Koshkina NV, Waldrep JC, Roberts LE, Golunski E, Melton S and Knight V: Paclitaxel liposome aerosol treatment induces inhibition of pulmonary metastases in murine renal carcinoma model. Clin Cancer Res 7: 3258-3262, 2001.

47. Fritz JM, Tennis MA, Orlicky DJ, Lin H, Ju C, Redente EF, Choo KS, Staab TA, Bouchard RJ, Merrick DT, et al: Depletion of tumor-associated macrophages slows the growth of chemically induced mouse lung adenocarcinomas. Front Immunol 5: 587, 2014

48. Wittgen BP, Kunst PW, van der Born K, van Wijk AW, Perkins W Pilkiewicz FG, Perez-Soler R, Nicholson S, Peters GJ and Postmus PE: Phase I study of aerosolized SLIT cisplatin in the treatment of patients with carcinoma of the lung. Clin Cancer Res 13: 2414-2421, 2007
49. OlivierKN,Griffith DE,EagleG,McGinnis JPII,MicioniL,Liu K, Daley CL, Winthrop KL, Ruoss S, Addrizzo-Harris DJ, et al: Randomized trial of liposomal amikacin for inhalation in nontuberculous mycobacterial lung disease. Am J Respir Crit Care Med 195: 814-823, 2017.

50. Zhang J, Leifer F, Rose S, Chun DY, Thaisz J, Herr T, Nashed M, Joseph J, Perkins WR and DiPetrillo K: Amikacin liposome inhalation suspension (ALIS) penetrates non-tuberculous mycobacterial biofilms and enhances amikacin uptake into macrophages. Front Microbiol 9: 915, 2018.

51. Okusanya OO, Bhavnani SM, Hammel J, Minic P, Dupont LJ, Forrest A, Mulder GJ, Mackinson C, Ambrose PG and Gupta R: Pharmacokinetic and pharmacodynamic evaluation of liposomal amikacin for inhalation in cystic fibrosis patients with chronic pseudomonal infection. Antimicrob Agents Chemother 53: 3847-3854, 2009

52. Konduri KS, Nandedkar S, Rickaby DA, Düzgüneş $\mathrm{N}$ and Gangadharam PR: The use of sterically stabilized liposomes to treat asthma. Methods Enzymol 391: 413-427, 2005

53. Chen X, Huang W, Wong BC, Yin L, Wong YF, Xu M and Yang Z: Liposomes prolong the therapeutic effect of anti-asthmatic medication via pulmonary delivery. Int J Nanomedicine 7: 1139-1148, 2012

54. Ng ZY, Wong JY, Panneerselvam J, Madheswaran T, Kumar P, Pillay V, Hsu A, Hansbro N, Bebawy M, Wark P, et al: Assessing the potential of liposomes loaded with curcumin as a therapeutic intervention in asthma. Colloids Surf B Biointerfaces 172: 51-59, 2018.

55. Komalla V, Allam VS, Kwok CL , Sheikholeslami B, Owen L, Jaffe A, Waters SA, Mohammad S, Oliver BG, Chen H and Haghi M: A phospholipid-based formulation for the treatment of airway inflammation in chronic respiratory diseases. Eur J Pharm Biopharm 157: 47-58, 2020.

56. Nahar K, Absar S, Patel B and Ahsan F: Starch-coated magnetic liposomes as an inhalable carrier for accumulation of fasudil in the pulmonary vasculature. Int J Pharm 464: 185-195, 2014

57. Wijagkanalan W, Kawakami S, Takenaga M, Igarashi R, Yamashita $\mathrm{F}$ and Hashida M: Efficient targeting to alveolar macrophages by intratracheal administration of mannosylated liposomes in rats. J Control Release 125: 121-130, 2008.

58. Cryan SA, Devocelle M, Moran PJ, Hickey AJ and Kelly JG: Increased intracellular targeting to airway cells using octaarginine-coated liposomes: In vitro assessment of their suitability for inhalation. Mol Pharm 3: 104-112, 2006.

59. Uner M and Yener G: Importance of solid lipid nanoparticles (SLN) in various administration routes and future perspectives. Int J Nanomedicine 2: 289-300, 2007.

60. Bi R, Shao W, Wang Q and Zhang N: Solid lipid nanoparticles as insulin inhalation carriers for enhanced pulmonary delivery. J Biomed Nanotechnol 5: 84-92, 2009

61. Nassimi M, Schleh C, Lauenstein HD, Hussein R, Lübbers K, Pohlmann G, Switalla S, Sewald K, Müller M, Krug N, et al: Low cytotoxicity of solid lipid nanoparticles in in vitro and ex vivo lung models. Inhal Toxicol 21: 104-109, 2009.

62. Videira M, Almeida AJ and Fabra A: Preclinical evaluation of a pulmonary delivered paclitaxel-loaded lipid nanocarrier antitumor effect. Nanomedicine 8: 1208-1215, 2012.

63. Castellani S, Trapani A, Spagnoletta A, di Toma L, Magrone T, Di Gioia S, Mandracchia D, Trapani G, Jirillo E and Conese M: Nanoparticle delivery of grape seed-derived proanthocyanidins to airway epithelial cells dampens oxidative stress and inflammation. J Transl Med 16: 140, 2018.

64. Bayón-Cordero L, Alkorta I and Arana L: Application of solid lipid nanoparticles to improve the efficiency of anticancer drugs. Nanomaterials (Basel) 9: 474, 2019.

65. Maretti E, Costantino L, Buttini F, Rustichelli C, Leo E, Truzzi E and Iannuccelli V: Newly synthesized surfactants for surface mannosylation of respirable SLN assemblies to target macrophages in tuberculosis therapy. Drug Deliv Transl Res 9: 298-310, 2019.

66. Nimje N, Agarwal A, Saraogi GK, Lariya N, Rai G, Agrawal H and Agrawal GP: Mannosylated nanoparticulate carriers of rifabutin for alveolar targeting. J Drug Target 17: 777-787, 2009.

67. Rytting E, Nguyen J, Wang X and Kissel T: Biodegradable polymeric nanocarriers for pulmonary drug delivery. Expert Opin Drug Deliv 5: 629-639, 2008.

68. Marasini N, Haque S and Kaminskas LM: Polymer-Drug conjugates as inhalable drug delivery systems: A review. Curr Opin Colloid Interface Sci 31, 2017. 
69. Yang M, Yamamoto H, Kurashima H, Takeuchi H, Yokoyama T, Tsujimoto $\mathrm{H}$ and Kawashima $\mathrm{Y}$ : Design and evaluation of poly(DL-lactic-co-glycolic acid) nanocomposite particles containing salmon calcitonin for inhalation. Eur J Pharm Sci 46 374-380, 2012.

70. Türeli NG, Torge A, Juntke J, Schwarz BC, Schneider-Daum N, Türeli AE, Lehr CM and Schneider M: Ciprofloxacin-Loaded PLGA nanoparticles against cystic fibrosis P. Aeruginosa lung infections. Eur J Pharm Biopharm 117: 363-371, 2017.

71. Kim I, Byeon HJ, Kim TH, Lee ES, Oh KT, Shin BS, Lee KC and Youn YS: Doxorubicin-Loaded highly porous large PLGA microparticles as a sustained- release inhalation system for the treatment of metastatic lung cancer. Biomaterials 33: 5574-5583, 2012.

72. Pandey R, Sharma A, Zahoor A, Sharma S, Khuller GK and Prasad B: Poly (DL-lactide-co-glycolide) nanoparticle-based inhalable sustained drug delivery system for experimental tuberculosis. J Antimicrob Chemother 52: 981-986, 2003.

73. Tomoda K, Ohkoshi T, Hirota K, Sonavane GS, Nakajima T, Terada H, Komuro M, Kitazato K and Makino K: Preparation and properties of inhalable nanocomposite particles for treatment of lung cancer. Colloids Surf B Biointerfaces 71: 177-182, 2009.

74. Zou W, Liu C, Chen Z and Zhang N: Studies on bioadhesive PLGA nanoparticles: A promising gene delivery system for efficient gene therapy to lung cancer. Int J Pharm 370: 187-195, 2009.

75. Dailey LA and Kissel T: New poly(lactic-co-glycolic acid) derivatives: Modular polymers with tailored properties. Drug Discov Today Technol 2: 7-13, 2005.

76. Xu Y, Kim CS, Saylor DM and Koo D: Polymer degradation and drug delivery in PLGA-based drug-polymer applications: A review of experiments and theories. J Biomed Mater Res B Appl Biomater 105: 1692-1716, 2017.

77. Fu J, Fiegel J, Krauland E and Hanes J: New polymeric carriers for controlled drug delivery following inhalation or injection. Biomaterials 23: 4425-4433, 2002.

78. Fatemeh DRA, Shahmabadi HE, Abedi A, Alavi SE, Movahedi F, Esfahani MKM, Mehrizi TZ and Akbarzadeh A: Polybutylcyanoacrylate nanoparticles and drugs of the platinum family: Last status. Indian J Clin Biochem 29: 333-338, 2014.

79. Melguizo C, Cabeza L, Prados J, Ortiz R, Caba O, Rama AR, Delgado ÁV and Arias JL: Enhanced antitumoral activity of doxorubicin against lung cancer cells using biodegradable poly(butylcyanoacrylate) nanoparticles. Drug Des Devel Ther 9: 6433-6444, 2015.

80. Choi WS, Murthy GG, Edwards DA, Langer R and Klibanov AM Inhalation delivery of proteins from ethanol suspensions. Proc Natl Acad Sci USA 98: 11103-11107, 2001.

81. Nam JP and Nah JW: Target gene delivery from targeting ligand conjugated chitosan-PEI copolymer for cancer therapy. Carbohydr Polym 135: 153-161, 2016.

82.Zhao L, Li Y, Pei D, Huang Q, Zhang H, Yang Z, Li F and Shi T: Glycopolymers/PEI complexes as serum-tolerant vectors for enhanced gene delivery to hepatocytes. Carbohydr Polym 205: $167-175,2019$

83. B. Thapa, R. Narain, 1-Mechanism, current challenges and new approaches for non viral gene delivery, Editor(s): Ravin Narain Polymers and Nanomaterials for Gene Therapy, Woodhead Publishing, 2016, Pages 1-27.

84. Germershaus O, Mao S, Sitterberg J, Bakowsky U and Kissel T: Gene delivery using chitosan, trimethyl chitosan or polyethylenglycol-graft-trimethyl chitosan block copolymers: Establishment of structure-activity relationships in vitro. J Control Release 125: 145-154, 2008.

85. Mehta M, Deeksha, Tewari D, Gupta G, Awasthi R, Singh H, Pandey P, Chellappan DK, Wadhwa R, Collet T, et al: Oligonucleotide therapy: An emerging focus area for drug delivery in chronic inflammatory respiratory diseases. Chem Biol Interact 308: 206-215, 2019.

86. Ahmad J, Akhter S, Rizwanullah Md, Amin S, Rahman M, Ahmad MZ, Rizvi MA, Kamal MA and Ahmad FJ: Nanotechnology-Based inhalation treatments for lung cancer: State of the art. Nanotechnol Sci Appl 8: 55-66, 2015.

87. Mendes LP, Pan J and Torchilin VP: Dendrimers as nanocarriers for nucleic acid and drug delivery in cancer therapy. Molecules 22: 1401, 2017.

88. Bellini RG, Guimarães AP, Pacheco MA, Dias DM, Furtado VR, de Alencastro RB and Horta BAC: Association of the anti-tuberculosis drug rifampicin with a PAMAM dendrimer. J Mol Graph Model 60: 34-42, 2015.
89. Rajabnezhad S, Casettari L, Lam JK, Nomani A, Torkamani MR, Palmieri GF, Rajabnejad MR and Darbandi MA: Pulmonary delivery of rifampicin microspheres using lower generation polyamidoamine dendrimers as a carrier. Powder Technol 291: 366-374, 2016.

90. Conti DS, Brewer D, Grashik J, Avasarala S and da Rocha SR Poly(amidoamine) dendrimer nanocarriers and their aerosol formulations for siRNA delivery to the lung epithelium. Mol Pharm 11: 1808-1822, 2014.

91. Zhong Q, Bielski ER, Rodrigues LS, Brown MR, Reineke JJ and da Rocha SR: Conjugation to poly(amidoamine) dendrimers and pulmonary delivery reduce cardiac accumulation and enhance antitumor activity of doxorubicin in lung metastasis. Mol Pharm 13: 2363-2375, 2016.

92. Inapagolla R, Guru BR, Kurtoglu YE, Gao X, Lieh-Lai M, Bassett DJP and Kannan RM: In vivo efficacy of dendrimer-methylprednisolone conjugate formulation for the treatment of lung inflammation. Int J Pharm 399: 140-147, 2010.

93. Mehta M, Deeksha, Sharma N, Vyas M, Khurana N, Maurya PK, Singh H, de Jesus TPA, Dureja H, Chellappan DK, et al: Interactions with the macrophages: An emerging targeted approach using novel drug delivery systems in respiratory diseases. Chem Biol Interact 304: 10-19, 2019.

94. Cortajarena AL, Ortega D, Ocampo SM, Gonzalez-García A, Couleaud P, Miranda R, Belda-Iniesta C and Ayuso-Sacido A: Engineering iron oxide nanoparticles for clinical settings. Nanobiomedicine (Rij) 1: 2, 2014.

95. Motomura K, Ishitobi M, Komoike Y, Koyama H, Noguchi A Sumino H, Kumatani Y, Inaji H, Horinouchi T and Nakanishi K SPIO-Enhanced magnetic resonance imaging for the detection of metastases in sentinel nodes localized by computed tomography lymphography in patients with breast cancer. Ann Surg Oncol 18: 3422-3429, 2011.

96. Yhee JY, Im J and Nho RS: Advanced therapeutic strategies for chronic lung disease using nanoparticle-based drug delivery. J Clin Med 5: 82, 2016.

97. Chen YH, Tsai CY, Huang PY, Chang MY, Cheng PC, Chou CH, Chen DH, Wang CR, Shiau AL and Wu CL: Methotrexate conjugated to gold nanoparticles inhibits tumor growth in a syngeneic lung tumor model. Mol Pharm 4: 713-722, 2007.

98. Brown SD, Nativo P, Smith JA, Stirling D, Edwards PR, Venugopal B, Flint DJ, Plumb JA, Graham D and Wheate NJ: Gold nanoparticles for the improved anticancer drug delivery of the active component of oxaliplatin. J Am Chem Soc 132: 4678-4684, 2010

99. Codullo V, Cova E, Pandolfi L, Breda S, Morosini M, Frangipane V, Malatesta M, Calderan L, Cagnone M, Pacini C, et al: Imatinib-Loaded gold nanoparticles inhibit proliferation of fibroblasts and macrophages from systemic sclerosis patients and ameliorate experimental bleomycin-induced lung fibrosis. J Control Release 310: 198-208, 2019.

100. Zhang J, Mou L and Jiang X: Surface chemistry of gold nanoparticles for health-related applications. Chem Sci 11: 923-936, 2020.

101. Omlor AJ, Le DD, Schlicker J, Hannig M, Ewen R, Heck S Herr C, Kraegeloh A, Hein C, Kautenburger R, et al: Local effects on airway inflammation and systemic uptake of $5 \mathrm{~nm}$ PEGylated and citrated gold nanoparticles in asthmatic mice. Small 13: 1002, 2017

102. Park H, Tsutsumi $\mathrm{H}$ and Mihara $\mathrm{H}$ : Cell-Selective intracellular drug delivery using doxorubicin and $\alpha$-helical peptides conjugated to gold nanoparticles. Biomaterials 35: 3480-3487, 2014.

103. Bhaskar S and Lim S: Engineering protein nanocages as carriers for biomedical applications. NPG Asia Mater 9: e371, 2017.

104. Syomin BV and Ilyin YV: Virus-Like particles as an instrument of vaccine production. Mol Biol 53: 323-334, 2019.

105. Bobo D, Robinson KJ, Islam J, Thurecht KJ and Corrie SR: Nanoparticle-Based medicines: A review of FDA-approved materials and clinical trials to date. Pharm Res 33: 2373-2387, 2016.

106. Renukaradhya GJ, Narasimhan B and Mallapragada SK: Respiratory nanoparticle-based vaccines and challenges associated with animal models and translation. J Controll Release 219 622-631, 2015

107. Coleman CM, Liu YV, Mu H, Taylor JK, Massare M, Flyer DC, Smith GE and Frieman MB: Purified coronavirus spike protein nanoparticles induce coronavirus neutralizing antibodies in mice. Vaccine 32: 3169-3174, 2014 
108. Smith G, Raghunandan R, Wu Y, Liu Y, Massare M, Nathan M Zhou B, Lu H, Boddapati S, Li J, et al: Respiratory syncytial virus fusion glycoprotein expressed in insect cells form protein nanoparticles that induce protective immunity in cotton rats. PLoS One 7: e50852, 2012.

109. Lee YT, Ko EJ, Kim KH, Hwang HS, Lee Y, Kwon YM, Kim MC, Lee YN, Jung YJ and Kang SM: Cellular immune correlates preventing disease against respiratory syncytial virus by vaccination with virus-like nanoparticles carrying fusion proteins. J Biomed Nanotechnol 13: 84-98, 2017.

110. Pápay ZE, Kósa A, Böddi B, Merchant Z, Saleem IY, Zariwala MG, Klebovich I, Somavarapu S and Antal I: Study on the pulmonary delivery system of apigenin-loaded albumin nanocarriers with antioxidant activity. J Aerosol Med Pulm Drug Deliv 30: 274-288, 2017.

111. Labiris NR and Dolovich MB: Pulmonary drug delivery. Part I: Physiological factors affecting therapeutic effectiveness of aerosolized medications. Br J Clin Pharmacol 56: 588-599, 2003.

112. Patton JS, Fishburn CS and Weers JG: The lungs as a portal of entry for systemic drug delivery. Proc Am Thorac Soc 1 338-344, 2004

113. Shen AM and Minko T: Pharmacokinetics of inhaled nanotherapeutics for pulmonary delivery. J Control Release 326: 222-244, 2020.

114. Scherließ R: Future of nanomedicines for treating respiratory diseases. Expert Opin Drug Deliv 16: 59-68, 2019.

115. Oberdörster G: Safety assessment for nanotechnology and nanomedicine: Concepts of nanotoxicology. J Intern Med 267: $89-105,2010$
116. Ferreira AJ, Cemlyn-Jones $\mathbf{J}$ and Cordeiro CR: Nanoparticles, nanotechnology and pulmonary nanotoxicology. Rev Port Pneumol 19: 28-37, 2013

117. Jones MC, Jones SA, Riffo-Vasquez Y, Spina D, Hoffman E, Morgan A, Patel A, Page C, Forbes B and Dailey LA: Quantitative assessment of nanoparticle surface hydrophobicity and its influence on pulmonary biocompatibility. J Control Release 183: 94-104, 2014.

118. Dailey LA, Jekel N, Fink L, Gessler T, Schmehl T, Wittmar M, Kissel $\mathrm{T}$ and Seeger W: Investigation of the proinflammatory potential of biodegradable nanoparticle drug delivery systems in the lung. Toxicol Appl Pharmacol 215: 100-108, 2006.

119. Zhang WF, Zhou HY, Chen XG, Tang SH and Zhang JJ: Biocompatibility study of theophylline/chitosan/beta-cyclodextrin microspheres as pulmonary delivery carriers. J Mater Sci Mater Med 20: 1321-1330, 2009.

120. Nakamura K, Matsubara H, Akagi S, Sarashina T, Ejiri K, Kawakita N, Yoshida M, Miyoshi T, Watanabe A, Nishii N and Ito $\mathrm{H}$ : Nanoparticle-Mediated drug delivery system for pulmonary arterial hypertension. J Clin Med 6: 48, 2017.

This work is licensed under a Creative Commons Attribution-NonCommercial-NoDerivatives 4.0 International (CC BY-NC-ND 4.0) License. 